\title{
A review of Japanese-style bathing: its demerits and merits
}

\author{
Yutaka Tochihara* ${ }^{*}$
}

\begin{abstract}
Japanese-style bathing (JSB), which involves soaking in hot water up to the shoulders in deep bathtubs for a long time in the evening to night, is unique. Many experimental and epidemiological studies and surveys have shown that JSB improve sleep quality, especially shortens sleep onset latency in winter. In addition, repeated JSB lead the improvement of depressive symptoms. JSB is a simple and low-cost non-pharmacological measure to sleep difficulty in winter and mental disorders, especially for the elderly. On the contrary, drowning, while soaking in a bathtub, is the most common of accidental death at home in Japan. It is estimated that approximately 19,000 Japanese individuals die annually while taking a bath, mostly during winter, and most victims are elderly people. Elderly Japanese people tend to prefer a higher-risk JSB because the temperature inside the house during winter, especially the dressing room/bathroom temperature, is very low. Since the physiological thermal effect of the elderly associated with bathing is relatively lower among the elderly than the young, the elderly prefer to take a long hot bath. This elderly's favorite style of JSB results in larger increased blood pressure in dressing rooms and larger decreased in blood pressure during hot bathing. A sudden drop in blood pressure while immersed in the bathtub leads to fainting and drowning. Furthermore, elderly people are less sensitive to cold air or hot water, therefore, it is difficult to take appropriate measures to prevent large fluctuations in blood pressure. To ensure a safe and comfortable winter bathing, the dressing room/ bathroom temperature needs to be maintained at $20^{\circ} \mathrm{C}$ or higher, and several degrees higher would be recommended for the elderly.
\end{abstract}

Keywords: Japanese-style bathing, Sudden death, Elderly, Blood pressure, Cold, Sleep

\section{Background}

\section{Japanese-style bathing}

Bathing styles vary worldwide, including bathtub bathing, sauna bathing, and showering. Each country has its own bathing style, such as the Finnish sauna $[1,2]$ and Turkish bath [3]. Japanese-style bathing (JSB), which involves soaking in hot water up to the shoulders in deep bathtubs for a long time in the evening to night, is unique and different from Western-style bathing. In the West, the water used for bathing is less hot, and people soak their chest in a long bathtub. In the west, people tend to wash their

*Correspondence: tochihara@kyudai.jp

Department of Human Science, Faculty of Design, Kyushu University,

4-9-1 Shiobaru, Minami-ku, Fukuoka 815-8540, Japan body in the bathtub, while Japanese people tend to have a washing space outside the bathtub [4-6]. One of the reasons why they clean their body outside the tub is that Japanese do not normally change the water between each bath.

Japanese people like bathing very much. Tokyo Gas Inc. investigated the bathing style of 2600 people (15-75 years) in the Tokyo metropolitan area, and reported that $85.7 \%$ of people liked soaking in a hot water bathtub [7]. Approximately $70 \%$ of people take a bath daily in the winter. The reasons why they like bathing are as follows: warming the body $(71.2 \%)$, recover from fatigue $(67.2 \%)$, relax the body $(65.9 \%)$, refresh their feelings $(37.2 \%)$, and be able to sleep well (35.8\%). original author(s) and the source, provide a link to the Creative Commons licence, and indicate if changes were made. The images or other third party material in this article are included in the article's Creative Commons licence, unless indicated otherwise in a credit line to the material. If material is not included in the article's Creative Commons licence and your intended use is not permitted by statutory regulation or exceeds the permitted use, you will need to obtain permission directly from the copyright holder. To view a copy of this licence, visit http://creativecommons.org/licenses/by/4.0/. The Creative Commons Public Domain Dedication waiver (http://creativeco mmons.org/publicdomain/zero/1.0/) applies to the data made available in this article, unless otherwise stated in a credit line to the data. 


\section{History of Japanese bathing}

In Japan, until the middle of the Edo period (1600-1864), bathing by storing steam in a room (steam bath) was common and had religious implications. Bathing through immersion of the body in hot water (hot water public bath) became widespread during the late eighteenth century. Home baths was widely practiced in the middle of the twentieth century $[6,8]$. The cultural anthropologist, Ruth Benedict, in her book entitled "The Chrysanthemum and the Sword" published in 1946, provided an explanation of sleep, food, love, and sake in the chapter "The circle of human feelings," and described the characteristics of the Japanese hot bath in detail [9]. "One of the best loved minor pleasures of the body in Japan is the hot bath. For the poorest rice farmer and the meanest servant, just as much as for the rich aristocrat, the daily soak in superlatively heated water is a part of the routine of every late afternoon. The commonest tub is a wooden barrel with a charcoal fire under it to keep the water heated to $110^{\circ}$ Fahrenheit and over. People wash and rinse themselves all over to before they get into the tub and then give themselves over to their enjoyment of warmth and relaxation of soaking. They sit in the bath with their knees drawn up in fetal position, the water up to their chins" [9].

There are various theories regarding why Japanese people prefer hot water baths in winter and take baths almost every day. First, indoor in Japanese houses are generally cold in winter $[10,11]$. In winter, to prevent feeling of cold after bathing, it may be necessary to soak in a hot water to stay warm [5]. Conventional Japanese houses have a structure that surpasses the heat and humidity of the summer. The ease of spending summer has long been prioritized in Japan. In the famous book "Essays in Idleness" by Kenko Yoshida in the Kamakura period (890910), "A house should be built with the summer in mind. In winter it is possible to live anywhere, but a badly made house is unbearable when it gets hot." [12]. Second, Japan has numerous water resources; hence, water supply is relatively cheap [13], so Japanese people do not hesitate in pouring hot water in the bathtub. Finally, there are many hot springs in Japan, increasing the opportunities to take hot spring baths, which may also be related factor.

\section{Sudden death during bathing}

By contrast, JSB in winter can causes serious health problems as well. It has been reported that there are many sudden deaths during JSB [5, 14-23]. Takahashi et al. [22] and Suzuki et al. [15] estimated that the annual number of deaths during bathing in Japan was 17,000 and 19,000 , respectively. Most cases occurred in winter, and the victims were mostly elderly people aged 65 and over. In Japan, the elderly population ratio account for $29.1 \%$ in 2021, and this ratio is expected to increase to $33.4 \%$ in 2035. Therefore, if effective measures are not taken, it has been warned that bathing deaths will reach 27,000 annually [15]. In Japan, which has reached a super-aged society, it is important to reduce the number of accidents related to bathing among the elderly population from the viewpoint of physiological anthropology.

This review aimed to summarize the effects of JSB on the human body. The effects were divided into two categories: demerits and merits. There are many benefits to JSB, such as warming of the body, recovery from fatigue, a refresh feeling, and enhanced sleep. In this review, we focused on evaluating the efficiency of JSB in improving sleep and depressive symptoms in winter. The demerit of JSB is sudden death during bathing of the elderly in winter. This review clarified why elderly people become victims during bathing in winter by conducting various physiological and psychological experiments and surveys on the effects of JSB, and also mention countermeasures against bathing accidents.

\section{Demerits of JSB}

\section{Accidental deaths at home}

Table 1 shows the number of accidental deaths at home announced by the Japanese Ministry of Health, Labor and Welfare 2019 [24]. A total number was 13,800 Japanese individuals die due to household accidents, of whom 11,987 (86.9\%) were 65 years old or older. "Drowning" (41.1\% of the total) was the most common cause of accidental death at home in the same year, followed by "asphyxiation" and "falls." "Drowning" was a summer accident in the sea bathing and pool long ago, but recently Matsui and Kagamimori [17] reported that many deaths occurred "in the bathtub (60\%)," of which $89 \%$ occurred at home, by age group, the number of elderly people who die during bathing is particularly high (85\%). Moreover, Suzuki et al. [23] investigated bathrelated deaths from all cases handled by the Tokyo Medical Examiner's Office from 2009 to 2011. The autopsy

Table 1 Number of accidental deaths at home in Japan in 2019

\begin{tabular}{llll}
\hline & Total & Over 65 years & (\%) \\
\hline Deaths in houses & 13,800 & 11,987 & 86.9 \\
Asphyxiation & 3187 & 2747 & 86.2 \\
Death by drowning & $\mathbf{5 6 7 3}$ & $\mathbf{5 3 1 0}$ & $\mathbf{9 3 . 6}$ \\
Death by fire & 813 & 602 & 74.0 \\
Death by falls & 2394 & 2088 & 87.2 \\
Others & 1733 & 1240 & 71.6 \\
Deaths by traffic accident & 4279 & 2508 & 58.6 \\
\hline
\end{tabular}


findings revealed that water inhalation was the primary cause of death in majority of the cases (79.1\%).

However, it is often reported that the cause of death during bathing is not only "drowning" but may also be heart disease, cerebrovascular disease, etc. The number of drowning deaths shown in the vital statistics of the Ministry of Health, Labor, and Welfare does necessarily indicate the number of deaths associated with bathing. Concerns were raised as the statistical provided did not represent the entire number of deaths from bathing. Therefore, the cases in which ambulances were requested to the fire departments in several prefectures were considered to clarify the reality of related fatal accidents [19]. As a result, "cardiopulmonary arrest," "heart disease," or "cerebrovascular disease," was often indicted as the cause of death in the death certificates of victims who died while taking a bath, "drowning" is rarely indicated as the cause of death in this patient group.

Takahashi et al. [22] of the Tokyo Metropolitan Institute of Health and Longevity Medical Center surveyed 634 fire departments nationwide, and determined that a total of 9360 elderly people experienced cardiac dysfunction while in the bathroom. Based on this number of cardiac arrest cases, it is estimated that approximately 17,000 people die annually while taking a bath. From these surveys, which evaluated bathing deaths, it has been clarified that bathing deaths are more common among the elderly people because three-fourths of the victims were aged 65 years and older $[16,19]$. Looking at the onset by month, it is clear that the cases are many in winter when the temperature is very low [25], and few in the summer, moreover, the number of bathing-related deaths in January, was 10.7 times higher than that in August, which has the lowest reports of deaths [22]. Suzuki et al. [15] also conducted a broad surveillance program in three areas and estimated that the annual number of deaths during bathing is 19,000 .

Do bathing-related deaths frequently occur among the elderly population worldwide? Lin et al. [26] compared the unintentional drowning mortality rate for 3 years in 60 countries by age and accident location. Japan reported a relatively low mortality rate $(0.9$ deaths per 100,000 population) among younger adults aged $15-24$ years, but had the highest mortality rate (19.0 deaths per 100,000 population) among the elderly aged $65+$ years. Figure 1 shows the distribution of accident locations among the three countries with the highest number of victims from drowning deaths among the 60 countries [26]. Japan had the highest number of victims from drowning and highest incidence of bathtub accidents (64.6\%). On the other hand, in the USA and Poland, drowning mostly occurred while swimming in pools, seas and rivers. The high number of deaths in bathtubs in winter among the elderly is

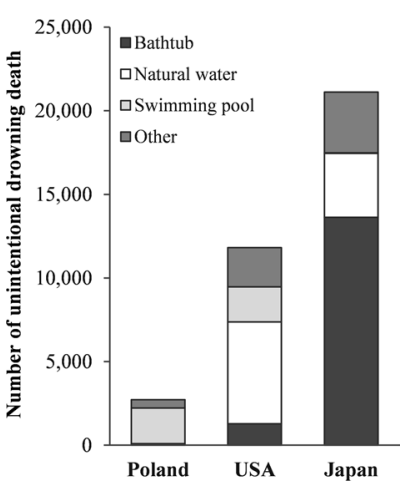

Fig. 1 Distribution of accident locations in Poland, USA and Japan

a characteristic event in Japan [21]. These deaths, associated with bathing, are common among the elderly in winter and are a prominent accident in Japan.

\section{Surveys on JSB}

To prevent Japanese bathing accidents, many surveys on bathing patterns (frequency, immersion depth, duration, time zone, etc.) and bathing environment (room temperature and hot water temperature) have been conducted. Kanda et al. [27] measured the temperature of the living rooms and dressing rooms of the detached houses of 42 elderly people living in North-Tokyo in winter, the average temperatures of these areas were only $15.0{ }^{\circ} \mathrm{C}$ and $13.5^{\circ} \mathrm{C}$, respectively, and the average hot water temperature was $40.8^{\circ} \mathrm{C}$. In the summer, the average temperature in the living room was $28.0^{\circ} \mathrm{C}$, that in the dressing room is $29.5^{\circ} \mathrm{C}$, and that of the average hot water temperature was $40.1{ }^{\circ} \mathrm{C}$, emphasizing the need to improve the thermal environment of the bathroom and dressing room in winter. Upon measuring SBP fluctuations associated with bathing, it was found that the SBP rose sharply when the individuals were naked while staying in a cold dressing room in winter, and the average SBP was greatly affected by room temperature.

We measured the thermal environments (living room, bathroom, dressing room, and outdoor air) of 331 detached houses in 11 regions (Sapporo, Akita, Sendai, North Chiba, South Chiba, Shizuoka, Toyama, Osaka, Hiroshima, Fukuoka, and Kagoshima) every minute for 1 week in winter [10]. In addition, a questionnaire survey regarding bathing habits was conducted among the elderly people who were living in the area [28]. Figure 2 shows the temperature by room (average value for 10 min of bathing) during winter bathing by region [10]. In each area, the temperature in the living room was high, and while that in the dressing room was the lowest. In Sapporo, the average temperature in the dressing 
room and bathroom, when naked and in cold stress, were $21.0{ }^{\circ} \mathrm{C}$ and $22.3{ }^{\circ} \mathrm{C}$, respectively, in other regions, the average temperature in the dressing room and bathroom were kept at $10-15{ }^{\circ} \mathrm{C}$ and $15-20^{\circ} \mathrm{C}$, respectively. Sapporo is geographically located more northward than other regions, and the outdoor temperature is very low in winter. Therefore, installation of heating systems widely practiced, and the temperatures in bathrooms and dressing rooms are relatively high. The relationship of drowning mortality rate with temperature of each room in the home was investigated by using a multivariate analysis. The only room temperature that showed a significant relationship with the drowning mortality rate by prefecture was the dressing room temperature. In Akita and Toyama, where the drowning mortality rate was high, the dressing room temperature was found to be low. It was shown that heating the dressing room was essential for preventing sudden death during bathing.

Takasaki et al. [29] conducted a questionnaire survey on bathing habits of 583 elderly people in four regions with different drowning mortality rates (low rate, Sapporo; medium rate, Osaka; high rate, Akita and Fukuoka). Sapporo and the other three regions were compared by conducting a logistics regression analysis; results showed that the winter bathing habits in Sapporo, the region with the lowest rate of mortality due to bathing accidents, are "less bathing," "short stay in the bathroom," "short soaking time in the bathtub" and "do not feel so cold while taking a bath." They reported that if the elderly people develop the abovementioned bathing habits, it can effectively prevent fatal bathing accidents.

Yatsuzuka et al. [30] conducted an online questionnaire survey (4161 people) to determine the bathroom specifications, heating equipment, and winter bathing habits of individuals living in detached houses and apartments in warm and cold regions. Approximately $68.4 \%$ of respondents took a bath daily, indicating that the older the person, the more often they take a bath in the bathtub. In addition, those who complained that the bathroom was cold in winter had a higher water temperature, had less satisfaction with bathing, and had a higher incidence of physical discomforts (dizziness, stagger, and hot flashes) while in the bathroom.

In summary, elderly people in Japan have a habit of bathing in a cold dressing room/bathroom in winter almost every day from evening to night in hot water of 40 ${ }^{\circ} \mathrm{C}$ or higher by soaking in the water up to their shoulders, this finding shows that such bathing habits will increase the elderly people's risk of illness.

\section{Physiological and subjective responses of the elderly related to JSB}

The reason why bathing deaths are more common among the elderly in winter is thought to be due to the subjective and physiological characteristics of the elderly in relation to the thermal environment during bathing.

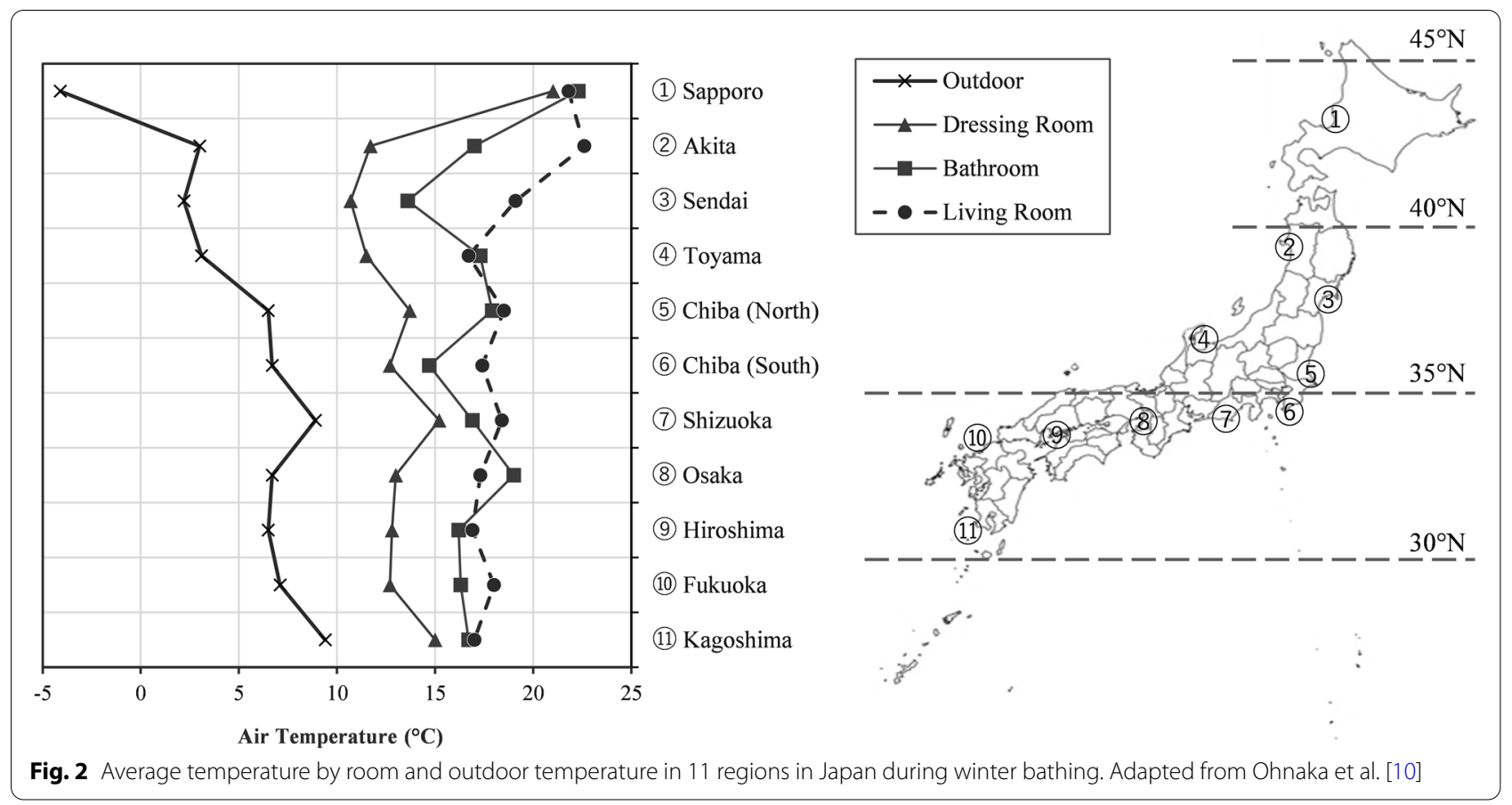




\section{Effects of cold exposure on thermal sensation and BP in the dressing room}

The dressing room is usually located outside the bathroom. The Japanese people first remove their clothes in the dressing room, and then enter the bathroom. In most Japanese detached houses, the dressing rooms and bathrooms are located on the north side and have poorly insulated windows [11]. Therefore, elderly people in Japan get naked in a cold dressing room before taking a bath in winter. Experiments were conducted to measure the thermal responses of the elderly and young people by exposing them to the cold of around $10{ }^{\circ} \mathrm{C}$ naked, and it was reported about 70 years ago that the elderly had less complaints of discomfort due to the cold [31]. However, no specific results were given. Therefore, Tochihara et al. [32] conducted an experiment comparing the feeling of coldness and warmth when elderly women and young women were exposed to cold $\left(10{ }^{\circ} \mathrm{C}\right)$ or hot $\left(35^{\circ} \mathrm{C}\right)$ for $50 \mathrm{~min}$ while dressed in nightwear. Results showed that although there was no difference in the feeling of coldness and warmth between the two groups after $30 \mathrm{~min}$ or more, there were significantly fewer complaints of coldness in the elderly immediately after exposure to the cold room. This finding indicates that elderly people have delayed sensitivity to cold and are more likely to tolerate cold.

The abovementioned experiments represented passive methods in determining the comfortable temperature. In contrast, active determination of the comfortable temperature can be carried out using a certain method. Each person can be allowed to control the temperature of the artificial climate room, and the change in room temperature can be recorded. Collins et al. [33] used this method to determine the comfortable temperature for young people and older people over 70 years old, no significant difference in preferred temperature was observed between young and old people. However, elderly people had less ability to control the temperature, and the fluctuations of selected temperature for elderly people were significantly larger than that for young people. Thus, elderly people have decreased sensitivity to temperature changes. Ohnaka et al. [34] and Taylor et al. [35] also conducted experiments in an artificial climate room to select the preferred temperature for the elderly and young people. Although there was no age difference in the preferred temperature, elderly people were less likely to complain of discomfort due to cold or hot temperature. Compared with young people, elderly people cannot control air conditioning properly, a greater thermal stimulus (cold/heat) is required. This finding indicates that special consideration is required when selecting the high and low temperature ranges for elderly people, especially in

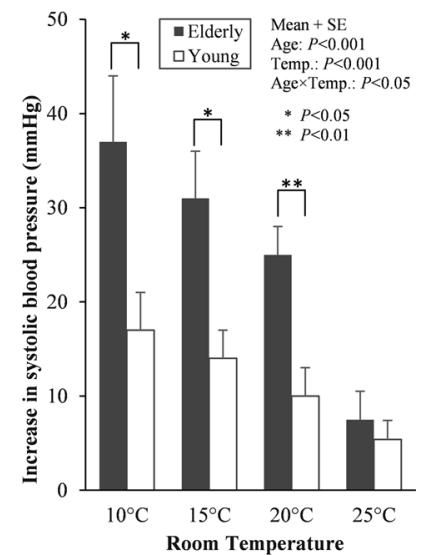

Fig. 3 Age-related differences in systolic blood pressure increases in the dressing room under four room temperature conditions. Adapted from Tochihara et al. [39]

cold environment, beyond the comfortable temperature range.

It is widely known that when the human body is exposed to cold, BP rises due to the vasoconstriction of the skin and internal organs, and this tendency is particularly strong in the elderly due to increase in vascular stiffening and deterioration of baroreceptor sensitivity [32, 36-38]. Tochihara et al. [39] focused on the age-related difference in SBP influenced by the dressing room temperature. The physiological response was measured while the elderly people were soaking in hot water $\left(40{ }^{\circ} \mathrm{C}\right)$ for 8 min up to the shoulder under the condition of room temperature of $10{ }^{\circ} \mathrm{C}, 15^{\circ} \mathrm{C}, 20^{\circ} \mathrm{C}$, and $25^{\circ} \mathrm{C}$. We showed the degree of increase in SBP due to cold exposure in the dressing room by group under each condition of room temperature as shown in Fig. 3. At room temperatures of $10{ }^{\circ} \mathrm{C}, 15{ }^{\circ} \mathrm{C}$, and $20{ }^{\circ} \mathrm{C}$, the degree of increase in BP was significantly greater in the elderly group; however, at room temperature of $25{ }^{\circ} \mathrm{C}$, there was no difference between the groups. At a room temperature of $20^{\circ} \mathrm{C}$, the younger group demonstrated an average BP increase of $10 \mathrm{mmHg}$ or less, while the elderly group demonstrated an average BP increase of $25 \mathrm{mmHg}$. Based on these findings, a room temperature of $20{ }^{\circ} \mathrm{C}$ was not sufficient for the elderly.

Recently, Tochihara et al. [38] investigated the age difference in physiological and subjective responses to a wide range of gradual ambient temperatures changes. We found no age difference in thermal sensation even though the BP of the elderly increased significantly during cold and rewarming periods. This gap could be explained by the blunted cutaneous thermal sensitivity thresholds in the elderly to warm and cold stimuli on their skin $[40,41]$. 
In summary, elderly people are less likely to feel the coldness of the dressing room, and do not consider it as unpleasant. On the contrary, elderly people tend to exhibit a higher BP upon exposure to the cold, and they require higher room temperatures to prevent a rapid increase in BP. A large increase in physiological burden without awareness may lead to accidents among elderly people while taking a bath.

\section{Effects of hot water immersion on subjective and physiological responses in bathtubs}

Although few studies have reported the age difference in sensitivity with respect to the temperature of hot water, Tochihara et al. [39] compared the thermal sensation of eight elderly people and eight young people when they were soaked in hot water, with a temperature of $40{ }^{\circ} \mathrm{C}$ up to their shoulders for $8 \mathrm{~min}$. On average, elderly people reported that they felt "slightly hot" while taking a bath, and young people reported that they felt "hot", showing a significant age difference. Ono et al. [42] compared the warmth and discomfort of 11 elderly people and 10 young people when they were soaked in hot water at 39 ${ }^{\circ} \mathrm{C}$ or $42{ }^{\circ} \mathrm{C}$ up to the axilla for $8 \mathrm{~min}$. The younger people showed a clear difference in thermal sensations between the hot water temperatures of $39^{\circ} \mathrm{C}$ and $42{ }^{\circ} \mathrm{C}$ at the end of bathing, while the elderly did not report a difference in thermal sensations between the hot water temperatures. In addition, only young people complained of discomfort due to heat when the water temperature was $42^{\circ} \mathrm{C}$. Miwa et al. [43] also compared the degree of warmth and discomfort of 10 elderly and 10 young people when they were soaked in hot water at $41{ }^{\circ} \mathrm{C}$ up to the chest for 15 min. For young people, while taking a bath, the changed from "slightly hot" or "hot", the elderly reported that it was almost "neutral." The discomfort changed from "slightly comfortable" to "uncomfortable" in young people, and the declaration of elderly people was "comfortable" from beginning to end. This difference in sensitivity to hot water may lead to the tendency of elderly people to increase the temperature of hot water when bathing in winter and increase the water level in the bathtub [30].

Experiments have been reported in which the physiological responses associated with bathing in the elderly were measured and compared with the young (8 to 12 participants in each group). Nagasawa et al. [44] measured the BP and electrocardiogram during bathing at a hot water temperature of $40{ }^{\circ} \mathrm{C}$ for $10 \mathrm{~min}$ and for $15 \mathrm{~min}$ before and after the bathing, and they performed heart rate variability analysis. In younger people, parasympathetic activity decreased, BP gradually decreased, and heart rate increased during bathing. On the other hand, in elderly people, no change was observed in parasympathetic nerve activity during bathing, and it was reported that BP and heart rate increased immediately after bathing and began to decrease in about $4 \mathrm{~min}$. Miwa et al. [45] compared the circulatory dynamics and thermoregulatory function when bathing in the axilla at a hot water temperature of $40{ }^{\circ} \mathrm{C}$ for $20 \mathrm{~min}$. Elderly people had a sharp rise in SBP immediately after bathing and a drop during bathing. They also admit that the range of BP fluctuations is larger than that of young people, the increase in heart rate during bathing relatively small, and the increase in core temperature and sweating during bathing was also small.

Ono et al. [42] compared the age differences in physiological responses when bathing at a hot water temperature of $39{ }^{\circ} \mathrm{C}$ or $42{ }^{\circ} \mathrm{C}$ for $8 \mathrm{~min}$. Focusing on the experiment with a hot water temperature of $42^{\circ} \mathrm{C}$, it was shown that the SBP and heart rate of the elderly increased immediately after bathing and decreased later. On the contrary, the heart rate of young people continued to increase while taking a bath. In addition, the amount of weight loss in the elderly was significantly small. Recently, Miwa et al. [43] compared the thermoregulatory response associated with bathing at a hot water temperature of $41^{\circ} \mathrm{C}$ for $15 \mathrm{~min}$ between the elderly and young. It was revealed that the increase in tympanic temperature, local sweating (arm), and skin blood flow (forearm) while taking a bath was relatively smaller in the elderly.

The above experiments were carried out at moderate room temperature $\left(20{ }^{\circ} \mathrm{C}\right.$ to $\left.26{ }^{\circ} \mathrm{C}\right)$, but Tochihara et al. [39] focused on the age difference due to the influence of bathroom/dressing room temperature. The physiological response when bathing in hot water at $40{ }^{\circ} \mathrm{C}$ for $8 \mathrm{~min}$ under room temperatures of $10{ }^{\circ} \mathrm{C}, 15^{\circ} \mathrm{C}, 20{ }^{\circ} \mathrm{C}$, and 25 ${ }^{\circ} \mathrm{C}$ was measured as shown in the previous section. The lower the room temperature in the dressing room/bathroom, the greater the degree of decrease in BP during bathing, which was particularly observed in the elderly. The elderly people were shown to have a greater decrease in BP when bathing in a cold room compared with younger people.

Fluctuations in the physiological response vary considerably depending on the hot water temperature, bathing time, room temperature, etc., the age difference in physiological fluctuations while performing JSB was summarized based on the following three experimental studies. The water temperature and immersion time reported by Nagasawa et al. [44], Miwa et al. [45], and Miwa et al. [43] were $40{ }^{\circ} \mathrm{C}$ for $10 \mathrm{~min}, 40{ }^{\circ} \mathrm{C}$ for $20 \mathrm{~min}$ and $41{ }^{\circ} \mathrm{C}$ for 15 $\mathrm{min}$, respectively. The water level of the bath was almost shoulder level in all three experiments. A conceptual diagram of age-related differences in physiological reactions during JSB is shown in Fig. 4 [46].

The SBP (A) of the elderly increased once due to the sympathomimetic effect called "surprise reflex" 
immediately after bathing [20] and then decreased more rapidly compared with that of the young. On the contrary, the increase in heart rate $(\mathrm{B})$, which is considered to be a compensatory function of the baroreceptor reflex to decrease the BP, of the elderly was much smaller than that of the young during bathing. It seems that the suppression of visceral parasympathetic nerve activity (F: heart rate variability; HF power) is less likely to occur in the elderly compared to the young [47]. That is, in the elderly, the BP and heart rate during bathing are not properly regulated by the autonomic nerves, resulting in a large decrease in BP of the elderly. It has been pointed out that this leads to "syncope" and the accompanying "drowning" [46]. In fact, it has been reported that more than $80 \%$ of people had their faces submerged in bathtubs at the scene of bathing deaths attended by paramedics [15].

Elderly people have a low increase in core temperature (C) and a small increase in sweating (D) and skin blood flow (E). The reason why the core temperature of the elderly is less likely to rise is that they generally have a larger amount of subcutaneous fat than the young and their body is less likely to warm up [45]. Furthermore, physiologically, the low sweating in the elderly was due to the delayed sweating start time and age-related decrease in sweat output per single sweat gland [48]. The small increase in cutaneous blood flow is due to the decrease in skin vasodilatory ability $[48,49]$.

In any case, elderly people prefer a long-term hightemperature bath and tend to immerse the shoulder because the physiological thermal effect associated with bathing is low and it is difficult to feel the heat of the hot water. This also seems to lead to an increase in bathing deaths among the elderly in winter.

\section{Prevention of sudden death during bathing}

"The methods for preventing elderly bathing death in winter" were published by several institutions (e.g., Consumer Affairs Agency, Japan [50]), and were as follows: (1) warming the dressing room/bathroom, (2) avoiding heating the water $\left(41^{\circ} \mathrm{C}\right.$ or less), (3) avoiding taking long baths (within $10 \mathrm{~min}$ ), (4) taking a half-body bath rather than a full-body bath, (5) avoiding rapidly getting up from the bathtub to prevent a rapid decrease in hydrostatic pressure, (6) drinking water before and after bathing to prevent dehydration, (7) encouraging elderly people to call out diligently when taking a bath, and (8) avoiding taking a bath when not feeling well or after drinking alcohol.

Regarding the points numbered (2), (3), and (4), high water temperature bath and long bath are preferred when the room temperature is low $[29,30]$, and a halfbody bath is not preferred because it is uncomfortable

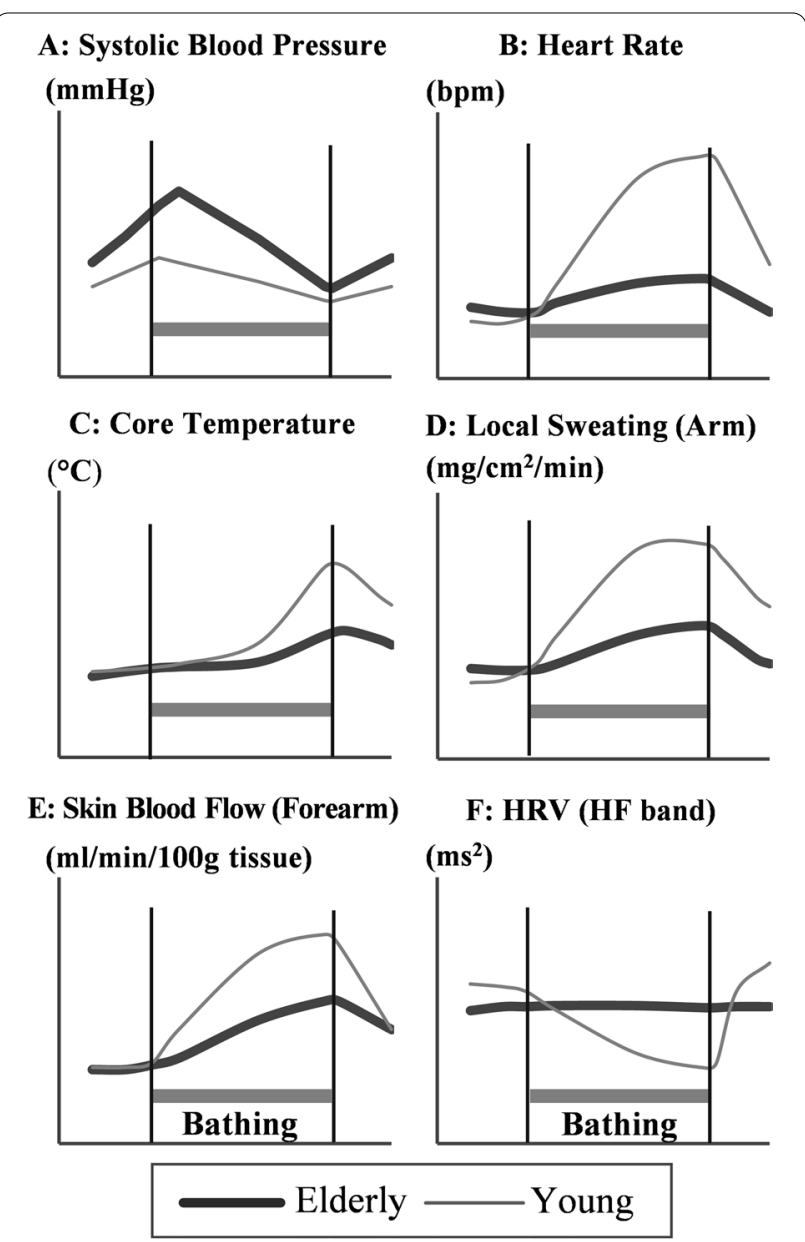

Fig. 4 Age-related differences in physiological reactions during JSB (conceptual diagram). Adapted from Tochihara and Hashiguchi [46]

and unrealistic in the cold environments [51]. That is, many surveys and experiments revealed that items (2), (3), and (4) can be resolved by warming the dressing room/bathroom. Therefore, I examined the recommended and permissible values of the dressing room/ bathroom temperature in winter, which is the key measures for preventing bathing death in the elderly in winter. The World Health Organization Guidelines for Housing and Health, published in 2018 [52], recommend a minimum room temperature of $18^{\circ} \mathrm{C}$ in winter.

When examining the relationship between the health of the elderly and the thermal environment, the BP is often used as the evaluation of physiological strain as described above. Collins et al. [36] investigated the BP fluctuations in the elderly and young when exposed to a temperature of $6{ }^{\circ} \mathrm{C}$ to $15{ }^{\circ} \mathrm{C}$ for $2 \mathrm{~h}$ in winter while dressed in nightwear. At room temperature of $6{ }^{\circ} \mathrm{C}$, the $\mathrm{BP}$ of young people tended to stabilize after increasing, while the $\mathrm{BP}$ of elderly people continued to increase. At a room temperature of $12{ }^{\circ} \mathrm{C}$, the $\mathrm{BP}$ of young people 
hardly increased, while in the elderly, the BP increased significantly. From the viewpoint of BP fluctuations, it was reported that the room temperature of the elderly should be kept at $15{ }^{\circ} \mathrm{C}$. Umishio et al. [53] conducted a large-scale winter housing survey from 2014 to 2017 to measure the BP and room temperature in the early morning and before bedtime of 2900 people (mean age 57 years). The room temperature at which SBP does not exceed $135 \mathrm{mmHg}$ was examined by age group and gender by conducting a detailed analysis; results showed that a room temperature of $19{ }^{\circ} \mathrm{C}$ or higher is required for men in their 70s.

However, these standard values represent the room temperatures when loungewear is worn. On the contrary, what should be the permission temperature of the dressing room/bathroom when an individual is naked? Tochihara [5] conducted a bathing experiment in which 12 young men were immersed in a hot water temperature at $40{ }^{\circ} \mathrm{C}$ for $8 \mathrm{~min}$ under seven conditions of room temperature of $5{ }^{\circ} \mathrm{C}, 10{ }^{\circ} \mathrm{C}, 15^{\circ} \mathrm{C}, 20^{\circ} \mathrm{C}, 25{ }^{\circ} \mathrm{C}, 30{ }^{\circ} \mathrm{C}$, and $35{ }^{\circ} \mathrm{C}$. The $\mathrm{BP}$ increased sharply at room temperature of $5{ }^{\circ} \mathrm{C}, 10^{\circ} \mathrm{C}$, and $15{ }^{\circ} \mathrm{C}$, and decreased at a room temperature of $35^{\circ} \mathrm{C}$. Therefore, the permissible room temperature range based on the $\mathrm{BP}$ was $20^{\circ} \mathrm{C}$ to $30^{\circ} \mathrm{C}$. Furthermore, it has been reported that a room temperature of $20^{\circ} \mathrm{C}$ or higher to prevent the increase in BP associated with bathing, and that the elderly should be kept warmer as shown in Fig. 3.

In summary, when bathing safely and comfortably in winter, the dressing room/bathroom temperature must be maintained at $20{ }^{\circ} \mathrm{C}$ or higher; for elderly people, it is safer to increase the room temperature by several degrees.

\section{Merits of JSB}

There are, however, many research reports on the beneficial effects of JSB on sleep [54-61], self-rated health $[58,59,62]$, rehabilitation $[63,64]$, fatigue $[60,62,65]$, depression [66, 67], and BP [68].

Tokyo Gas Inc. [7] conducted a survey among 2600 people living in the Tokyo metropolitan area to determined their daily bathing habits in winter. The average current Japanese bathing habits were as follows: set temperature of hot water; $40-42{ }^{\circ} \mathrm{C}(71.8 \%)$, duration in bathroom; $26.4 \mathrm{~min}$, immersion time in bathtub; $13.7 \mathrm{~min}$, and bathing time; 20:00-23:00. Ishizawa et al. [62] reported that soaking in hot water bathing up to the shoulders was commonly practiced (83.3\%) in Japan. Tai et al. [67] also conducted a survey among 1035 elderly participants living in Nara Prefecture to assess their bathing habits in winter. The mean bathing start time, bedtime, bathing duration and hot water temperature were $20: 31,22: 31,13 \mathrm{~min}$, and $40.7{ }^{\circ} \mathrm{C}$, respectively.

It is difficult to achieve a deep sleep, and the time taken to fall asleep is extended in old age [69]. In early studies of the effects of bathing on sleep the warm bath of $41-43{ }^{\circ} \mathrm{C}$ temperature in an immersion tank or bathtub, with immersion of the whole body up to mid-thorax or neck high for 30-90 min with a 10-30 min interim cooling down period were performed in 1980s [70-73]. They reported that warm baths could enhance slow-wave sleep, reduce rapid eye movement (REM) sleep, and decrease sleep onset latency (SOL) in heathy young adults. As a physiological mechanism by which passive body heating (PBH) brings a good sleep, it has been suggested that the mechanism by means of which PBH affects sleep is that warming promotes a subsequent sleep fall in core body temperature, mimicking the decrease in core body temperature seen in the hours proceeding habitual bedtime $[74,75]$. Since 2000 , many studies $[55,76]$ reported that foot baths as well as bathtub baths improve sleep quality. A footbath is especially recommended for people with disability who are unable to enjoy regular baths easily and safely. Kräuchi and colleagues [77, 78] revealed increased distal vasodilation, as indicated by the distalproximal skin temperature gradient (DPG), and shorter SOL by PBH. They showed that a greater DPG could predict shorter SOLs in healthy individuals. Tai et al. [61] also showed similar results in an epidemiological study among 1094 elderly people (mean age, 72.0 years). They revealed that hot water bathing before bedtime in home settings is significantly associated with shorter actigraphic/self-reported SOL and higher DPG in a largescale older population. They suggested that bathing for 1-3 h before bedtime showed significantly shorter SOL, and higher DPG 30 min after bedtime.

In the experiments performed in 1980s; however, the participants immersed themselves in the baths for more than $30 \mathrm{~min}$, and their body core temperature increased about $1.6-2.6{ }^{\circ} \mathrm{C}$, these values are higher than those practicing the JSB (about $0.6-1.0{ }^{\circ} \mathrm{C}$ ). Therefore, their experiments did not directly show the effect of JSB on sleep. Thus, this article reviews the studies that assessed the effects of JSB on sleep as shown in Table 2. The only studies listed in the table are JSBs as defined below: water temperature, $40-41{ }^{\circ} \mathrm{C}$; bathing duration, $10-30 \mathrm{~min}$; immersion level, mid-thorax to neck; and bathing time, evening to night. Studies on the effects of showers and foot baths, bathing too hot, bathing too long, and bathing in the morning and early evening on sleep were excluded. However, studies conducted outside Japan, demonstrated that the bathing style is similar to the characteristics of JSB, are listed in the Table 2 [79-81]. Liao [84] reviewed the effects 
of bathing on body temperature and sleep regulation in the elderly from three studies including our study [54]. The review showed that bathing immersed to mid-thorax with $40-41{ }^{\circ} \mathrm{C}$ water for $10-30 \mathrm{~min}$ in the evening can increase the duration of slow-wave sleep in healthy elderly women, even in those with insomnia. Recently, Haghayegh et al. [85] reviewed by a meta-analysis to evaluate the effects of body heating by taking warm showers, foot baths or bathing on the quality of sleep in 13 studies, including our study [55]. They concluded that body heating in 40-42.5 ${ }^{\circ} \mathrm{C}$ water for a duration as short as 10 min scheduled $1-2$ $\mathrm{h}$ before bedtime is associated with shortened SOL and increased sleep efficiency. The bathing conditions they considered to provide good sleep were in good agreement with the JSB above as we defined.

Of the nine studies shown in Table 2, the one by Dowdell and Javaheri [79] did not report an improvement in sleep quality from baseline. The main cause was that the participants were patients with apnea/hypopnea syndrome. Other experiments that were conducted for comparison did not also report improvements in sleep quality due to the following reasons: the water temperature was low $\left(38.0{ }^{\circ} \mathrm{C}[80]\right.$;), the time before bedtime was too long (5.3 $\mathrm{h}$ [71];), PBH was footbath [55] and the time before bedtime was very short (0.3 $\mathrm{h}$ [82];). Bunnell et al. [72] investigated the effects of timing of bathing on sleep, namely morning (within $1 \mathrm{~h}$ of awakening), afternoon (10 $h$ before bedtime), early evening ( $6 \mathrm{~h}$ before bedtime), and late evening (just before bedtime). They showed that sleep onset time was reduced by bathing, particularly during early evening bathing. However, the bathing duration $\left(60 \mathrm{~min}\right.$ immersion at $\left.41{ }^{\circ} \mathrm{C}\right)$ was exceeded that of JSB. Sung et al. [82] compared the quality of postbath sleep $1.5 \mathrm{~h}$ before bedtime with that just before bedtime, and showed that bathing just before bedtime did not improve sleep quality. Browman and Tepas [86] investigated the effects of different pre-sleep activities on all-night sleep. They reported that the SOL was clearly prolonged when performing exercise immediately before going to bed. Continued physical excitement prevents the onset of sleep. JSB performed just before bedtime may have caused a great burden on the sympathetic nervous system and suppressed the onset of REM sleep [71].

One of the effects that the elderly people expect from bathing is the promotion of sleep onset in winter [7]. However, although there have been studies conducted in the laboratory on the effects of bathing on sleep, none have investigated the effects of JSB at home on sleep objectively. We evaluated the quality of sleep after bathing in the elderly by measuring "body movement" [54]. This is because polysomnography (PSG) interferes with sleep, especially in the elderly. In winter, 30 elderly people aged $65-83$ years ( 13 men and 17 women) and 30 young people aged $17-22$ years (10 men and 20 women) were surveyed in their homes. The survey was conducted by comparing the days when people slept after bathing for at least $10 \mathrm{~min}$, and the days when they did not take a bath. The measurement items were body movement number, rectal temperature, feeling of warmth and coldness, and feelings of sleepiness. The bedroom temperature was $8-12{ }^{\circ} \mathrm{C}$ for both age groups, and these temperatures were approximately the same as the average bedroom temperature $\left(12.8{ }^{\circ} \mathrm{C}\right)$ in recently detached homes [11]. Figure 5 shows the number of body movements every 30 min during sleep for the elderly and young. Although the number of body movements in the young group tended to be higher than that in the elderly group as a whole, the number of body movements up to $3 \mathrm{~h}$ after bedtime in both groups was significantly higher after bathing than in the control group. It was found that bathing in winter improved the quality of sleep in the first half of sleep. According to the reports received after waking up, elderly people often reported that "sleep onset", and "deep sleep" improved after bathing.

JSB can also ameliorate sleep disturbances in patients with insomnia [80, 81] and dementia [56]. JSB habits appear to have led to improvements in self-rated health $[58,59]$ and depressive symptoms [62, 66, 67, 87]. In an epidemiological study, Aritake-Okada et al. [57] investigated the relationship between daytime sleepiness and coping with regular behavior (having a bath, reading or listening to music, eating and drinking, etc.) to obtain adequate sleep in 24,686 general adults in Japan. They reported that "having a bath" was the most prevalent non-pharmacological self-management practice, especially for the elderly. Bathing reduced the daytime sleepiness complaints, and was associated with improved quality of nighttime sleep. On the contrary, exercising (USA) and reading (Canada) were most actively adopted as self-management practice for sleeping by participants in studies conducted outside Japan [57]. This may be attributable to the unique characteristics of JSB. Since sleep disturbance is known to be associated with the onset of mental disorders such as depression [88, 89], JSB can be a favorable practice that improves mental symptoms such as depression. Yagi et al. [66] investigated the association between a higher frequency of hot water bathing and lower depressive symptoms. They found that participants (4466 Japanese elderly) who took baths more frequently were less likely to be depressed after 3 years. In particular, it was shown that bathing in winter has a great effect of suppressing the onset of depression. Yagi et al. [87] also indicated that a high frequency of tub bathing is associated with lower onset of functional disability including depression among Japanese older adults. Recently, Tai et al. [67] showed interesting results from a 


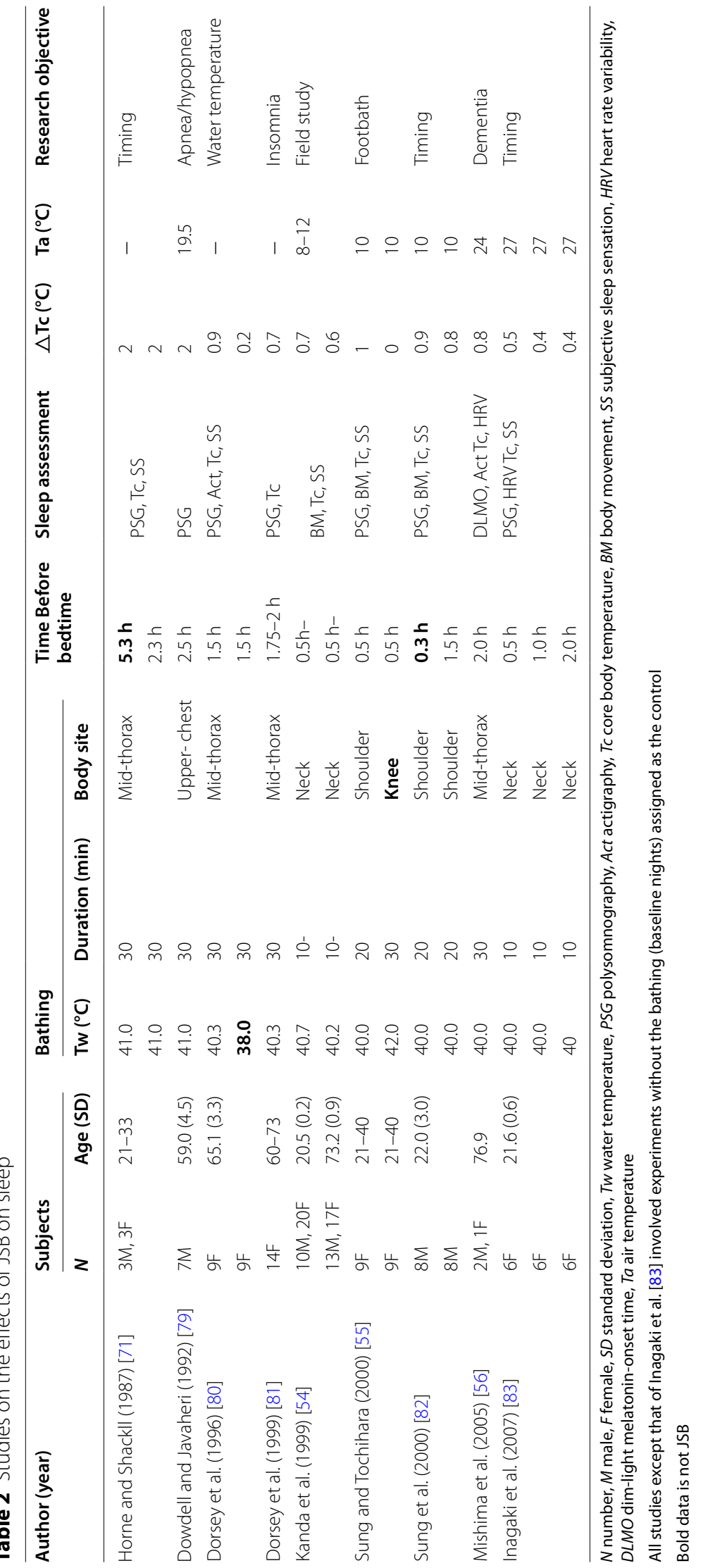



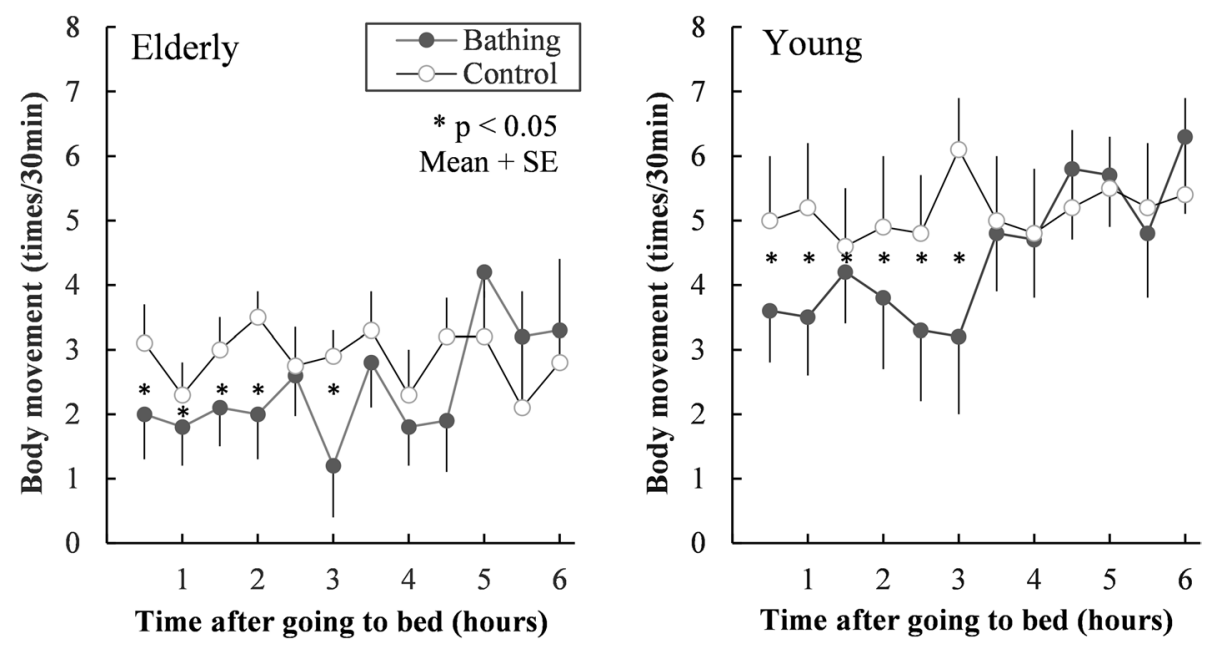

Fig. 5 Number of body movements every 30 min during sleep in the elderly and the young. Comparison between the after bathing and the control. Adapted from Kanda et al. [54]

logistic regression analysis of JSB habits and depression symptoms. They divided 1103 older volunteers by days of taking a bath in 2-day survey into three groups. Compared with the both-day bathing group, the either-day and no bathing groups were significantly associated with higher odds of depression symptoms. Moreover, they showed that shorter time before bedtime was associated with lower odds of depression symptoms.

In recent decades, the proportion of JSB has decreased, and the number of bathing styles that only require showering has increased (4.5\%), especially in younger ages (men in their 20s; 14.5\%), and the bathing style has become more westernized [7]. However, Yasuda et al. [60] reported the superior efficacy of JSB compared with showering. The study included were 18 university students who only showered on a daily basis, half of them continued to take a shower, while the other half adopted the JSB (10 min immersion at $41{ }^{\circ} \mathrm{C}$ water) for 2 weeks. They concluded that changing the bathing style from shower to JSB improves the participant's quality of sleep and work efficiency. Moreover, the percentage of Japanese who like JSB remained high at $80 \%$, and the dressing room temperature in winter in Japan $\left(13.0^{\circ} \mathrm{C}\right.$ average value from 2190 detached houses) remained low [11] compared with those in Europe and the USA [90]. Future research related to JSB on human health and comfort is still desired.

In summary, JSB, which involves immersion of the body from mid-thorax to neck in $40-41{ }^{\circ} \mathrm{C}$ water for $10-30$ $\mathrm{min}$ at $0.5-2.0 \mathrm{~h}$ before bedtime, can improve sleep quality, especially shortening of SOL. JSB is a simple and lowcost non-pharmacological measure of sleep difficulties in winter, especially for the elderly. Moreover, JSB can be a favorable practice that could prevent the onset of mental disorders such as depression.

\section{Conclusions}

Japanese people like hot water bathing and often soak their body up to the shoulders in deep bathtubs for a long time in the evening to night. Experimental and epidemiological studies have shown that JSB shortens SOL and improves sleep sensation in winter. JSB is a simple and low-cost non-pharmacological measure for improving sleeping difficulty in winter, especially for the elderly. Moreover, JSB can be a favorable practice that could prevent the onset of mental disorders such as depression. On the contrary, drowning, which commonly occurs in bathtubs, is the most common cause of accidental death at home in Japan. It is estimated that approximately 19,000 Japanese individuals die annually while taking a bath, most accidents occur in winter, and most victims are elderly. Elderly people are likely to prefer a higher-risk JSB because the room temperature inside the house during winter in Japan, especially the dressing room/ bathroom temperature, is very low. Since the physiological thermal effect of the elderly associated with bathing is relatively lower among the elderly than the young, the elderly prefer to take a long hot bath. This elderly's favorite style of JSB results in larger increased BP in dressing rooms and larger decreased in BP during hot bathing. A sudden drop in BP while immersed in the bathtub leads to fainting and drowning. Furthermore, elderly people are less likely to feel cold or hot water, therefore, it is difficult to take appropriate measures. For safe and comfortable winter bathing, the dressing room temperature needs to be maintained at $20^{\circ} \mathrm{C}$ or higher, and several degrees higher would be recommended for the elderly. 


\section{Abbreviations}

BP: Blood pressure; DPG: Distal-proximal skin temperature gradient; HF: High frequency; JSB: Japanese-style bathing; PBH: Passive body heating; PSG: Polysomnography; REM: Rapid eye movement; SBP: Systolic blood pressure; SOL: Sleep onset latency.

\section{Acknowledgements}

I would like to express my thanks to Prof. Ping Yea Loh, Prof. Yuji Takasaki, Ms. Sachi Takahashi and Ms. Shizuka Umezaki for their academic advice and technical support.

\section{Author's contributions}

YT wrote all this manuscript. The author read and approved the final manuscript.

\section{Funding}

This study was supported in part by a Grant-in-Aid for Scientific Research from the Japan Society for the Promotion of Science (\#25282014).

\section{Availability of data and materials}

All data generated or analyzed during this study are included in this published article.

\section{Declarations}

Ethics approval and consent to participate

Not applicable.

\section{Consent for publication}

Not applicable.

\section{Competing interests}

The author declares no competing interests.

Received: 8 November 2021 Accepted: 27 January 2022

Published online: 15 February 2022

\section{References}

1. Luurila OJ. Cardiac arrhythmias, sudden death and the Finnish sauna bath. Adv Cardiol. 1978;25:73-81.

2. Laukkanen T, Khan H, Zaccardi F, Laukkanen JA. Association between sauna bathing and fatal cardiovascular and all-cause mortality events. JAMA Intern Med. 2015;175(4);542-8.

3. Eren B, Fedakar R, Turkmen N, Akan O. Deaths in the Turkish human (hot bath). Bratisl Lek Listy. 2009;110:697-700.

4. Koren L. How to take a Japanese bath? Berkeley: Stone Bridge Press; 1992.

5. Tochihara Y. Bathing in Japan: A review. J Hum Environ Syst. 1999;3:27-34.

6. Traphagan JM. Culture and long-term care: the bath as social service in Japan. Care Manag J. 2004;5:53-60.

7. Tokyo Gas Inc. Current situation of the manner of bathing in Japan (in Japanese). Urban Life Res Inst. 2015:1-123 Available from: https://www. toshiken.com/report/docs/hot34-summary.pdf.

8. Clark S. Japan, a review from the bath. Honolulu: University of Hawaii Press; 1994.

9. Benedict R. The chrysanthemum and the sword -patterns of Japanese culture. Tokyo: Tuttle Publishing; 1946.

10. Ohnaka T, Takasaki Y, Tochihara Y, Nagai Y, H. I, Yoshitake S. A survey on thermal conditions of bathroom during winter in Japan (in Japanese). J Hum Living Environ. 2007;14:11-6.

11. Umishio W, Ikaga T, Fujino Y, Ando S, Kubo T, Nakajima Y, et al. Disparities of indoor temperature in winter: a cross-sectional analysis of the National Smart Wellness Housing survey in Japan. Indoor Air. 2020;30:1317-28.

12. Yoshida K. (Translated by Donald Keene). Essays in Idleness. Tokyo: Tuttle Publishing; 1985.

13. Thermaticmapping.org. 2016. Available from: http://thematicmapping. org/downloads/world_borders.php. Accessed 20 Sept 2021.
14. Chiba T, Yamauchi M, Nishida N, Kaneko T, Yoshizaki K, Yoshioka N. Risk factors of sudden death in the Japanese hot bath in the senior population. Forensic Sci Int. 2005;149:151-8.

15. Suzuki M, Shimbo T, Ikaga T, Hori S. Sudden death phenomenon while bathing in Japan - mortality data. Jpn Circ Soc. 2017;81:1144-9 Available from: https://doi.org/10.1253\%2Fcircj.cj-16-1066.

16. Takahashi R, Asakawa Y, Hamamatsu A. Deaths during bathing in Japan. J Am Geriatr Soc. 2007;55:1305-6.

17. Matsui T, Kagamimori S. Descriptive epidemiology of accidental drowning in the Bathtub (in Japanese). J Health Welf Stat. 2009;56:16-21.

18. Hayasaka S, Shibata Y, Noda T, Goto Y, Ojima T. Incidence of symptoms and accidents during baths and showers among the Japanese general public. Japan Epidemiol Assoc. 2011;21:305-8 Available from: https://doi. org/10.2188\%2Fjea.je20100136.

19. Ohtsuka $Y$, Inokuma S, Sugimoto $H$. Analysis of bathing related accidents in Japan -Collaboration with Japanese association for acute medicine. J Jpn Soc Balneol Clim Phys Med. 2011;74:239-45.

20. Okuda T, Shiotani S. Bath-related sudden death. In Sudden Death. Wu J WJ, editor. New York: Nova Science Publishers. Inc; 2013.

21. Satoh F, Ogawa M, Hasegawa I, Seto Y, Tsuboi A. "Death in hot bathtub" phenomenon: Accidental drawing or natural disease? Am J Forensic Med Pathol. 2013;34:164-8.

22. Takahashi R, Sakamoto Y, Tsuzuki K, Asakawa Y. Actual conditions of cardiopulmonary arrest (CPA) during bathing in Japan -Analysis of 9,360 cases of emergency transport in 47 prefectures- (in Japanese). Tokyo Metrop Geriatr Hosp Inst Gerontol. 2014:99-106.

23. Suzuki H, Hijiki W, Tanifuji T, Abe N, Fukunaga T. Characteristics of sudden bath-related death investigated by medical examiners in Tokyo, Japan. J Epidemiol. 2015;25:126-32.

24. Japanese Ministry of Health, Labor and Welfare. 2019. Available from: https://www.e-stat.go.jp/dbview?sid=0003411678. Accessed 20 Aug 2021.

25. Suzuki M, Ikaga T, Hori S. Relationship between bath-related deaths and lower air temperature. Intern Med. 2017;56:3173-7.

26. Lin CY, Wang YF, Lu TH, Kawachi I. Unintentional drowning mortality, by age and body of water: an analysis of 60 countries. Inj Prev. 2015;21:43-50.

27. Kanda K, Tsuchiya J, Seto M, Ohnaka T, Tochihara Y. Thermal conditions in the bathroom in winter and summer, and physiological responses of the elderly during bathing. Jpn J Hyg. 1995;50:595-603.

28. Takasaki Y, Ohnaka T, Tochihara Y, Nagai Y, Ito H, Yoshitake S. Environmental and behavioral conditions of bathing among elderly Japanese. J Physiol Anthropol. 2007;26:235-40.

29. Takasaki Y, Nagai Y, Inoue K, Maki M, Ohnaka T, Tochihara Y. Bathing habits of theelderly in winter and factors affecting regional differences in bathing date rate (in Japanese). J Hum Living Environ. 2011;18:99-106.

30. Yatsuzuka H, Inoue T, Mae M, Y M. Actual stage of bathing facilities and thermal environment (in Japanese). J Environ Eng AIJ. 2013;78:489-96.

31. Krag CL, Kountz WB. Stability of body function in the aged - effect of exposure of the body to cold. J Gerontol. 1950;5:227-35.

32. Tochihara Y, Ohnaka T, Nagai Y, Tokuda T, Kawashima Y. Physiological responses and thermal sensations of the elderly in cold and hot environments. J Therm Biol. 1993:18:355-61.

33. Collins KJ, Exton Smith AN, C D. Urban hypothermia: Preferred temperature and thermal perception in old age. Br Med J. 1981;282:175-7.

34. Ohnaka T, Tochihara Y, Tsuzuki K, Nagai Y, Tokuda T, Kawashima Y. Preferred temperature of the elderly after cold and heat exposures determined by individual self-selection of air temperature. J Therm Biol. 1993;18:349-53.

35. Taylor NAS, Allsopp NK, Parkers DG. Preferred room temperature of young vs aged males: the influence of thermal sensation, thermal comfort, and affect. J Gerontol. 1995;50A:216-21.

36. Collins KJ, Easton JC, Belfield- Smith H, Exton-Smith AN, Pluck PA. Effects of age on body temperature and blood pressure in cold environments. Clin Sci. 1985:69:465-70.

37. Hess KL, Wilson TE, Sauder CL, Gao Z, Ray CA, Monahan KD. Aging affects the cardiovascular responses to cold stress in humans. J Appl Physiol. 2009;107:1076-82.

38. Tochihara Y, Yamashita K, Fujii K, Kaji Y, Wakabayashi H, Kitahara H. Thermoregulatory and cardiovascular responses in the elderly towards 
a broad range of gradual air temperature changes. J Therm Biol. 2021;99:103007.

39. Tochihara Y, Hashiguchi N, Yadoguchi I, Kaji Y, Shoyama S. Effects of room temperature on physiological and subjective responses to bathing in the elderly. J Hum Environ Syst. 2012;15:13-9.

40. Tochihara Y, Kumamoto T, Lee J-Y, Hashiguchi N. Age-related differences in cutaneous warm sensation thresholds of human males in thermoneutral and cool environments. J Therm Biol. 2011;36:105-11.

41. Inoue Y, Gerrett N, Ichinose-Kuwabara T, Mano T, Ueda H, Havenith G, et al. Sex differences in age-related changes on peripheral warm and cold innocuous thermal sensitivity. Physiol Behav. 2016;164:86-92.

42. Ono J, Hashiguchi N, Sawatari H, Ohkusa T, Miyazono M, Son SY, et al. Effect of water bath temperature on physiological parameters and subjective sensation in older people. Geriatr Gerontol Int. 2017;17:2164-70.

43. Miwa C, Shimasaki H, Mizutani M, Mori Y, Maeda K, Deguchi A. Effect of aging on thermoregulatory and subjective responses during a 15-minute bath at $41^{\circ} \mathrm{C}$. J Human-Environment Sys. 2020;23:45-53.

44. Nagasawa Y, Komori S, Sato M, Tsuboi Y, Umetani K, Watanabe Y, et al. Effects of hot bath immersion on autonomic activity and hemodynamics -Comparison of the elderly patient and the healthy young. Jpn Circ J. 2001;65:586-92.

45. Miwa C, Sugimura K, Kawamura Y, Deguchi A, Iwase S. Effect of aging on cardiovascular and thermoregulatory function during $40^{\circ} \mathrm{C}$ bathing in humans (in Japanese). J Jpn Soc Balneol Clim Phys Med. 2002;65:187-93.

46. Tochihara Y, Hashiguchi N. Sudden death during bathing of the elderly in winter in Japan (in Japanese). J Hum Living Environ. 2021;28:53-64.

47. Kataoka Y, Yoshida F. The change of hemodynamics and heart rate variability on bathing by the gap of water temperature. Biomed Pharmacother. 2005;59:592-9.

48. Inoue Y, Shibazaki M. Regional differences in age-related decrements of cutaneous vascular and sweating responses to passive heating. Eur $J$ Appl Physiol. 1996;74:78-84.

49. Kenny GP, Poiriera MP, Metsiosc GS, Boulayd P, Dervisa S, Friesen SD, et al Hyperthermia and cardiovascular strain during an extreme heat exposure in young versus older adults. Temperature. 2017:4:79-88.

50. Consumer Affairs Agency. Be careful about accidents during bathing of elderly people that occur frequently in winter! New Release; 2020. p. 1-6.

51. Hashiguchi $\mathrm{N}, \mathrm{Ni}$ F, Tochihara Y. Effects of room temperature on physiological and subjective responses during whole-body bathing, half-body bathing and showering. J Physiol Anthropol. 2002;21:277-83.

52. World Health Organization. Hous. Heal. Guidel. 2018. Available from: https://apps.who.int/iris/bitstream/handle/10665/276001/97892 41550376-eng.pdf. Accessed 9 Feb 2020.

53. Umishio W, Ikaga T, Kario K, Fujino Y, Hoshi T, Ando S, et al. Cross-sectional analysis of the relationship between home blood pressure and indoor temperature in winter. Ovid Technologies (Wolters Kluwer Health). 2019;74:756-66 Available from: https://doi.org/10.1161\%2Fhypertensiona ha. 119.12914

54. Kanda K, Tochihara Y, Ohnaka T. Bathing before sleep in the young and in the elderly. Eur J Appl Physiol. 1999:80:71-5.

55. Sung EJ, Tochihara Y. Effects of bathing and hot footbath on sleep in winter. J Physiol Anthropol. 2000;19:21-7.

56. Mishima Y, Hozumi S, Shimizu T, Nishikawa Y, Mishima K. Passive body heating ameliorates sleep disturbances in patients with vascular dementia without circadian phase-shifting. Am J Geriatr Psychiatry. 2005;13:369-76

57. Aritake-Okada S, Kaneita Y, Uchiyama M, Mishima K, Ohida T. Nonpharmacological self-management of sleep among the Japanese general population. J Clin Sleep Med. 2009;5(5);464-9.

58. Hayasaka S, Shibata Y, Y. G, Noda T, Ojima T. Bathing in a bathtub and health status: A cross-sectional study. Comlement Ther Clin Pr. 2010;16:219-21.

59. Goto Y, Hayasaka S, Nakamura Y. Bathing in hot water, bathing in Japanese style hot spring and drinking green tea may contribute to the good health status of Japanese. J Jpn Soc Balneol Clim Phys Med. 2012;75:256-67.

60. Yasuda T, Kubo T, Masumitsu Y. Behavior change from the shower bathing to bath bathing affects sleep and working efficiency (in Japanese). J Jpn Soc Balneol Clim Phys Med. 2015;78:341-52.
61. Tai Y, Obayashi K, Yamaguchi Y, Yoshimoto K, Kurumatani N, Nishio K, et al. Hot-water bathing before bedtime and shorter sleep onset latency are accompanied by a higher distal-proximal skin temperature gradient in older adults. J Clin Sleep Med. 2021;17:1257-66.

62. Ishizawa T, Watanabe S, Yano S, Aburada M, Miyamoto K, Ojima T, et al. Relationship between bathing habits and physical and psychological state. J Jpn Soc Balneol Clim Phys Med. 2012;75:227-36.

63. Kamioka H, Mori Y, Nagata K, Iwanaga S, Uzura M, Yamaguchi S. Relationship of daily hot water bathing at home and hot water spa bathing with underlying diseases in middle-aged and elderly ambulatory patients: A Japanese multicenter cross-sectional study. Complement Ther Med. 2019:43:232-9.

64. Mooventhan A, Nivethitha L. Scientific evidence-based effects of hydrotherapy on various systems of the body. Medknow. 2014;6:199 Available from: https://doi.org/10.4103\%2F1947-2714.132935.

65. da Silva FM, de Oliveira SMJV, Nobre MR. A randomised controlled trial evaluating the effect of immersion bath on labour pain. Midwifery. 2009;25:286-94.

66. Yagi A, Hayasaka S, Ojima T. The association between tub-bathing frequency and the incidence of depression symptoms among older people in Japan: JAGES Iongitudinal study (in Japanese). Jap J Heal Res. 2019:40:67-73

67. Tai Y, Obayashi K, Yamaguchi Y, Kurumatani N, Saeki K. Association between passive body heating by hot water bathing before bedtime and depressive symptoms among community - dwelling older adults. Am 」 Geriatr Psychiatry. 2022;30(2);161-70.

68. Kawabe H, Saito I. Influence of nighttime bating on evening home blood pressure measurements: how long should the interval be after bathing? Hypertens Res. 2006;29:129-33.

69. Kim K, Uchiyama M, Okawa M, Liu X, Ogihara R. An epidemiological study of insomnia among the Japanese general population. Sleep. 2000;23:41-7.

70. Horne JA, Reid AJ. Night-time sleep EEG changes following body heating in warm bath. Electroencephalogr Clin Neurophysiol. 1985;60:154-7.

71. Horne JA, Shackell BS. Slow wave sleep elevations after body heating: proximately to sleep and effects of aspirin. Sleep. 1987;10:383-92.

72. Bunnell DE, Agnew JA, Horvath SM, Jopson L, Wills M. Passive body heating and sleep: influence of proximity to sleep. Sleep. 1988;11:210-9.

73. Jordan J, Montgomery I, Trinder J. The effect of afternoon body heating on body temperature and slow wave sleep. Psychophysiology. 1990;27:560-6.

74. Murphy PJ, Campbell SS. Nighttime drop in body temperature: A physiological trigger for sleep onset? Sleep. 1997;20:505-11.

75. Raymann RJEM, Swaab DF, Van Someren EJW. Skin temperature and sleep-onset latency: changes with age and insomnia. Physiol Behav. 2007:90:257-66.

76. Kim HJ, Lee Y, Sohng KY. The effects of footbath on sleep among the older adults in nursing home: A quasi-experimental study. Complement Ther Med. 2016;26:40-6.

77. Kräuchi K, Cajochen C, Werth E, Wirz-Justice A. Warm feet promote the rapid onset of sleep. Nature. 1999;401:36-7.

78. Kräuchi K, Cajochen C, Werth E, Wirz-Justice A. Functional link between distal vasodilation and sleep onset latency? Am J Physiol Regul Integr Comp Physiol. 2000;278:741-8.

79. Dowdell WT, Javaheri S. Lack of effect of external warming on sleep architecture in sleep apnea/hypopnea syndrome. Am Thorac Soc. 1992;145:137-40 Available from: https://doi.org/10.1164\%2Fajrccm\% 2F145.1.137.

80. Dorsey CM, Lukas SE, Teicher MH, Harper D, Winkelman JW, Cunningham $S L$, et al. Effects of passive body heating on the sleep of older female insomniacs. J Geriatr Psychiatry Neurol. 1996;9:83-90.

81. Dorsey CM, Teicher MH, Cohen-Zion M, Stefanovic I, Satlin A, Tartarini $W$, et al. Core body temperature and sleep of older female insomniacs before and after passive body heating. Sleep. 1999;22:891-8.

82. Sung EJ, Tochihara Y, Kim JS. Effects of the timing of bathing on sleep in winter. J Physiol Anthropol Appl Human Sci. 2000;19:122.

83. Inagaki J, Mahbub MH, Harada N. Effects of timing of warm bathing on night sleep in young healthy subjects. Bull Yamaguchi Med Sch. 2007;54:9-17. 
84. Liao WC. Effects of passive body heating on body temperature and sleep regulation in the elderly: a systematic review. Int J Nurs Stud. 2002;39:803-10.

85. Haghayegh S, Khoshnevis S, Smolensky MH, Diller KR, Castriotta RJ. Before-bedtime passive heating by warm shower or bath to improve sleep: A systematic review and meta-analysis. Sleep Med Rev. 2019:46:124-35.

86. Browman CP, Tepas DI. The effects of pre-sleep activity on all-night sleep. Psychophysiology. 1976;13:536-40.

87. Yagi A, Hayasaka S, Ojima T, Sasaki Y, Tsuji T, Miyaguni Y, et al. Bathing frequency and onset of functional disability among Japanese older adults: A prospective 3-year cohort study from the JAGES. J Epidemiol. 2019:29:451-6.

88. Kim K, Uchiyama M, Liu X, Shibui K, Ohida T, Ogihara R, et al. Somatic and psychological complains and their correlations with insomnia in the Japanese. Psychosom Med. 2001;63:441-6.

89. Almeida OP, Alfonso H, Yeap BB. Complaints of difficulty to fall asleep increase the risk of depression in later life: the health in men study. J Affect Disord. 2011;134:208-16.

90. Vadodaria K, Loveday DL, Haines V. Measured winter and spring-time indoor temperature in UK homes over the period 1969-2010: a review and synthesis. Energy Policy. 2014;64:252-62.

\section{Publisher's Note}

Springer Nature remains neutral with regard to jurisdictional claims in published maps and institutional affiliations.

- fast, convenient online submission

- thorough peer review by experienced researchers in your field

- rapid publication on acceptance

- support for research data, including large and complex data types

- gold Open Access which fosters wider collaboration and increased citations

- maximum visibility for your research: over $100 \mathrm{M}$ website views per year

At BMC, research is always in progress.

Learn more biomedcentral.com/submissions 